\title{
Suicidal Ideation and Attempts during Middle Childhood: Associations with Subjective Quality of Life and Depression
}

\author{
Sylvie Bourdet-Loubère ${ }^{*}$, Jean-Philippe Raynaud ${ }^{2}$ \\ ${ }^{1}$ Laboratoire LCPI, Université Toulouse II, Toulouse, France \\ ${ }^{2} \mathrm{CHU}$ de Toulouse, Toulouse, France \\ Email: "bourdet@univ-tlse2.fr
}

Received December 13, 2012; revised January 6, 2013; accepted January 26, 2013

Copyright (C) 2013 Sylvie Bourdet-Loubère, Jean-Philippe Raynaud. This is an open access article distributed under the Creative Commons Attribution License, which permits unrestricted use, distribution, and reproduction in any medium, provided the original work is properly cited.

\begin{abstract}
Background: Confronted to the increasing suicide rate in children, clinicians have to better understand and predict suicide-related behaviours (SRBs) in children with and without depressive symptoms. Aims: To investigate associations among suicidal tendencies (thoughts and/or attempts), depression and children's perceptions of subjective quality of life. Methods: This was a cross-sectional study of 157 children of 6 - 13-year-old. Results: Children who attempted or thought of suicide reported goodless subjective quality of life than nonsuicidal children did, and children who thought of or attempted suicide reported higher levels of depressive symptoms than nonsuicidal children. Limitations: A more rigorous approach to investigating suicidal ideation and depressive symptomatology as a diagnostic interview based on the DSM-IV-TR will be valuable to future progress in understanding children's suicidality. Conclusions: Results may reflect the confirmation of depressive symptoms as risk factors for suicidality and underline the high importance of social and emotional life context among suicidal children. For this reason, more effective recognition and comprehension of the underlying affective and social conditions of children with suicidality have special importance to prevent future suicidal behaviour during adolescence.
\end{abstract}

Keywords: Suicide Ideation; Suicide Attempt; Subjective Quality of Life; Depression; Children

\section{Introduction}

During the last several decades, suicide rate in young people has increased in several countries [1]. Recent worldwide annual suicide rates for children ages 5 - 14 are 0.5 per thousand for females and 0.9 per thousand for males [2]. In France, 37 completed suicide in children ages 5 - 14 were deplored in 2009 (cépi-DC, Inserm). Although the scientific literature suggests that children under 12 can display suicidal behavior and thinking [3,4], specific data describing suicidality in young children are relatively scarce and inconsistent [5]. Tishler et al. think this fact may be due in part to the ideas described previously, which children are too cognitively and/or developmentally immature to express suicidal feelings [6]. They add other reasons for the lack of these data in children younger than 12 years, including underreporting of known suicides (particularly by parents) and mistaken

"Corresponding author. classification of completed suicide and attempts as accidents $[7,8]$. If the prevalence of completed suicide among children, particularly those under age 11 , is effectively relatively low, suicidal ideation is much more common. But due to variations in the definitions, sample characteristics, and lack of accurate statistics, the prevalence rates of suicidal ideations and suicide attempts are difficult to estimate. However, it has been estimated that up to $25 \%$ of young people have had suicidal ideation and it is approximately estimated that the rate of suicide attempts is at least 20 times greater than that of completed suicide (WHO Mental Health, 2006). In 2003, suicide rates were 0.0 per 100,000 for ages 0 to 4 years, 0.6 per 100,000 for ages 5 to 14 years (250 deaths), and 9.7 per 100,000 for ages 15 to 24 years (3988 deaths). According to the same report, 68 children younger than 12 years committed suicide. The youngest child was aged 5 years old, and five 9 years old also committed suicide [9]. The suicide rate for children ages 5 to 14 years skyrocketed in 
the past (an increase of 267\% from 1970s rates of 0.3 per 100,000 to rates of 0.8 per thousand in 1986). This rate then decreased in 1996 (302 deaths) to current levels (250 deaths) [5]. Even with this decrease, suicide remained the 12th leading cause of death among children 12 years and younger in 2003. In addition, suicide was the fourth leading cause of death for 12 years old [9]. Only a few studies examine the rates of attempted suicide for prepubertal youth $[10,11]$. Some studies examining suicidal ideation in young children also demonstrate some variability in frequency estimates and differences in age groupings. Gould found that $1.9 \%$ out of their sample of 1285 randomly selected children aged 7 - 12 years reported suicidal ideation [12]. In contrast, Thompson found that approximately $10 \%$ of their sample of 10518 years old expressed suicidal ideation [13]. But this high level of suicidal ideation is not surprising, because the participants in the study by Thompson consisted of children who had previously been or were currently at high risk for maltreatment and/or abuse. On the other hand, some studies show that the most alarming suicidal ideation and attempts rates are seen in samples of child psychiatric inpatients: indeed, about $12 \%$ of normal school children 6 to 12 years old entertain suicidal thoughts, whereas $25 \%$ to $33 \%$ of outpatient and $72 \%$ to $79 \%$ of inpatient samples report suicidal ideation [14]. In support of this view, Rosenbaum Asarnow examined the suicidal ideation and attempts of 6- to 13-year-old psychiatric inpatients [15]. Seventeen in 55 (31\%) of the children had a history of suicidal ideation, and 19 in 55 (34.5\%) made at less an attempt. This suggests that the roots of suicidal behaviour may become salient in childhood and serve as the basis for future ideation and attempts [16]. Although young children appear to have some developmental and environmental protections from death by suicide, there is a dramatic increase in suicide rates in adolescence. Kovacs et al. have made a follow-up evaluation showing the rate of ideation remained relatively stable (62\%) whereas the number of suicide attempts doubled [17]. Thus, we have some evidence of the persistence and consequences of suicide ideation in childhood. Identifying and measuring constructs that aid in distinguishing high-risk children seem particularly important, before these children enter the high-risk adolescent period. Research with adults provides strong evidence that psychiatric illness, particularly depression, has been consistently associated with suicidality [18]. This suggests that depressive children who have a suicide history may represent a particularly high-risk group for recurrent and increasingly dangerous suicidal behaviour. But depression alone; however, cannot account for many children who think about and attempt suicide. For example, it is possible to identify and discriminate among children who are depressed, those who are depressed and suicidal, and those who are suicidal but not depressed or also those who are depressed and nonsuicidal. Depression and suicidal ideation may overlap but they are distinguishable. And other variables are likely to mediate the depression-suicide relation. For example, Asarnow showed that suicidal behavior was associated with a tendency for children to perceive their families as low in control and cohesiveness and high in conflict [19]. Suicidal children also spontaneously generated significantly fewer cognitive mediational strategies for coping with stressful life events than nonsuicidal children. Another research examined family psychopathology, child maltreatment, family instability, negative family environment, and negative peer relationships as early negative life events, and self-esteem, locus of control, field dependence, hopelessness, and problem-solving deficits as cognitive variables with the aim to propose a model linking these variables with suicide [20]. In this study, we hypothesize that a potentially useful construct for differentiating suicidal (ideators and attempters) and nonsuicidal children is subjective quality of life. So, we have examined suicidal ideations and attempts in 6- to 13year-old children and we have compared depressive symptoms and subjective quality of life according to suicidality. In keeping with our clinical practice, we predicted that suicidal children (ideators and attempters) would score higher on measures of depression and would hold a more negative subjective quality of life conception than their non-suicidal counterparts. Additional aims are 1) to better know which QOL's domains are the most degraded in suicidal children; 2) to clarify the degree of association among depressive symptoms, suicide-related behaviours and subjective quality of life.

\section{Methods}

\subsection{Study Population}

This was a cross-sectional study of 157 participants conducted in 2010 in South-West of France. The total sample $(n=157)$ consisted of $6-13$ years old children, the mean age ( \pm standard deviation, s) was $11.1 \pm 1.1$ year. The number of boys and girls was nearly equal (72 girls vs. 85 boys). Two groups were identified: 67 children were psychiatric inpatients (30 boys and 37 girls; $10.7 \pm$ 0.8 ) and 90 normal-school children (42 boys and 48 girls; $11.44 \pm 0.7)$. Participants and their families/guardians were required to provide written consent before participation. Exclusion criteria included a diagnosis of pervasive developmental disorder, evidence of a major neurological condition, a psychotic disorder, bipolar disorder, or Attention Deficit Hyperactivity Disorder (ADHD) combined type.

\subsection{Measures}

Depressive symptoms were assessed using the Child De- 
pression Inventory [21], a 27-item self-report inventory designed to measure the severity of depressive symptomatology in children between the ages of 7 and 17 years. This inventory has been widely used in previous studies. Each item of the CDI is composed of three choices. The child simply marks the choice that best describes his or her feelings or behavior over the past 2 weeks. This usually requires less than 15 minutes. Results can be scored and profiled in just 10 minutes more. The test provides a Total Score plus five Factor Scores: Negative Mood, Interpersonal Problems, Ineffectiveness, Anhedonia, and Negative Self-Esteem. A score that falls below a cut-off point, or is 1.0 to 2.0 standard deviations above the mean, is considered to be positive for depression (cut-off: 19). Scores can also be plotted as follows: minimal depression or none (0 - 9), mild depression (10 - 16), moderate (17 - 29), and severe depression (30 - 63). The French version of the CDI was validated by Moor \& Mack [22] and the internal consistency of the French version of the CDI is in agreement with the literature $(0.71$ for no depressed subjects and 0.89 for depressed patients and the test-retest coefficients range from 0.74 to 0.83 (time interval two-three weeks) [23]. Suicidal tendencies were assessed as (0) "never had serious thoughts of suicide", or (1) "ever had serious thoughts about suicide", (2) "ever had a plan to commit suicide", or (3) "ever attempted to commit suicide” (item n 9, CDI, Kovacs, 1985). The Kidscreen (Ravens-Sieberer, 2001) was used to evaluate subjective quality of life. It consists of 52 items, each scored on a five-point scale. The instrument includes total score and 10 subscale scores: Physical Well-being (5 items), Psychological Well-being (5 items), Moods \& Emotions (7 items), Peers \& Social Support (6 items), Parent Relation \& Home life (6 items), Self Perception (5 items), Autonomy (5 items), School Environment (6 items), Social Acceptance (Bullying) (3 items) and Financial Resources (3 items). The Kidscreen-52 questionnaire was developed simultaneously in several different countries. It was tested in a large representative sample of children and adolescents [24]. The Kidscreen and its French version are well researched and have adequate psychometric properties [25].

\subsection{Procedure}

For psychiatric inpatients, referrals to the clinic were invited to participate in the study, with over 95\% agreeing to participate. Once written consent was obtained, a child-and-adolescent psychiatrist and a supervised trainee clinical psychologist undertook the assessment procedure. For normal school children, referrals to the school were invited in the study, with approximately $50 \%$ agreeing to participate. The questionnaires were administered to participants who completed the above self-report measures.

\subsection{Data Analysis}

Data analysis was performed using the Statistica package (Statsoft), version 10.

The comparison of the CDI and Kidscreen scores was studied with the one-way analysis of variance. The differences between categorical variables were studied with the chi-square test and univariate logistic regression analysis. The numeric variables were categorized into two groups (clinical and normal range functioning) when they were taken into univariate logistic regression analysis. Odds ratios (OR) and their 95\% confidence intervals (95\% CI) were calculated for significant associations. P-values less than 0.05 were interpreted as significant.

\section{Results}

\subsection{Background Characteristics of the Subjects}

As shown in Table 1 , about twenty per cent $(n=32)$ of all of the children had presented suicidal thoughts or threats, while $6.3 \%(n=10)$ had ever made a suicide attempt. In this sample, $73.24 \%$ of the children didn't present clinical range for depression and $85.35 \%$ reported a good subjective quality of life.

\subsection{Associations with Suicidality}

Children with suicidal thoughts, threats and attempts were pooled together $(n=42)$ and compared with nonsuicidal children (115). Sixteen boys (18.8\%) and 26 girls (36.1\%) were suicidal, but the gender difference was not significant. On the other hand, group ages comparison showed that 20 children less or equal 11 years old and 22 more 11 years old were suicidal and the group

Table 1. Characteristics of the population $(n=157)$.

\begin{tabular}{lcc}
\hline & Gender & N \\
\hline Girl & & 72 \\
Boy & Age & 85 \\
& & \\
$<11$ & & 97 \\
$>12$ & Suicidality & 60 \\
& & 115 \\
No & & 32 \\
Thoughts or threats & & 10 \\
Acts & CDI & 137 \\
& & 20 \\
Normal range & & 134 \\
Clinical range & KIDSCREEN & 23 \\
\hline
\end{tabular}

${ }^{*}$ High level indicates good quality of life. 
ages difference was significant $(\mathrm{p}=0.022)$.

As shown in Table 2, factors being significantly associated with suicidality in chi-square comparisons were: group ages $(p=0.022)$ : $36.6 \%$ of kids over 12 had suicidal thoughts or acts versus $20.6 \%$ of kids under 11 years; depression symptoms ( $\mathrm{p}=0.01)$ : nearly $24 \%$ of children with suicidality and $8.7 \%$ of nonsuicidal children had a symptomatology of depression and a low Kidscreen level (0.001): $30 \%$ of children with suicidality, and $8.6 \%$ of nonsuicidal children, had a low level of quality of life. Furthermore, Kidscreen's sub-scores of Self-perception, Mood and emotions and Autonomy were significantly associated with suicidality $(\mathrm{p}<0.5)$. More than thirty seven percent of children with low score for self perception had suicidal thoughts as well as $42.59 \%$ with low score for moods and emotions and 34.84\% with low scores for autonomy. No significant differences were found in the chi-square comparison in others subscales of Kidscreen. But in univariate logistic regression analysis, low level for Parent Relation \& Home life with Kidscreen and strong level of depression with CDI were significantly associated with suicidality.

Table 3 compares the CDI scores and Kidscreen ratings of children with suicidality and nonsuicidal children using the analysis of variance. Children with suicidality had significantly higher CDI total score. Furthermore, they had significantly lower level on quality of life, es-

Table 2. Associations concerning suicidal ideation and behavior.

\begin{tabular}{|c|c|c|c|c|c|}
\hline Variable & $\mathrm{N}$ & $\begin{array}{c}\% \text { of subjects } \\
\text { are suicidal }\end{array}$ & OR & $(95 \% \mathrm{CI})$ & $\mathrm{p}$ \\
\hline \multicolumn{6}{|c|}{ Group Ages } \\
\hline$<11$ & 97 & 20.61 & 1.406 & $(0.999-1.980)$ & \multirow[t]{2}{*}{0.022} \\
\hline$>12$ & 60 & 36.66 & 0.631 & $(0.428-0.930)$ & \\
\hline \multicolumn{6}{|c|}{ CDI } \\
\hline Normal range & 137 & 23.35 & 1.198 & $(1.00-1.43)$ & \multirow[t]{2}{*}{0.015} \\
\hline Clinical range & 20 & 50 & 0.365 & $(0.164-0.815)$ & \\
\hline \multicolumn{6}{|c|}{ Kidscreen } \\
\hline Low level & 23 & 56.52 & 0.281 & $(0.133-0.592)$ & \multirow[t]{2}{*}{0.001} \\
\hline High leve $^{\mathrm{l}^{*}}$ & 134 & 21.64 & 1.322 & $(1.072-1.632)$ & \\
\hline \multicolumn{6}{|c|}{ Self-perception } \\
\hline Low level & 51 & 37.25 & 0.615 & $(0.394-0.959)$ & \multirow[t]{2}{*}{0.032} \\
\hline High level $^{*}$ & 106 & 21.69 & 1.318 & $(0.979-1.774)$ & \\
\hline \multicolumn{6}{|c|}{ Moods \& Emotions } \\
\hline Low level & 54 & 42.59 & 0.492 & $(0.327-0.740)$ & \multirow[t]{2}{*}{0.001} \\
\hline High level $^{*}$ & 103 & 18.44 & 1.615 & $(1.137-2.293)$ & \\
\hline \multicolumn{6}{|c|}{ Autonomy } \\
\hline Low level & 66 & 34.84 & 0.683 & $(0.475-0.981)$ & \multirow[t]{2}{*}{0.039} \\
\hline High level $^{*}$ & 91 & 20.87 & 1.384 & $(0.964-1.987)$ & \\
\hline
\end{tabular}

*High level indicates good quality of life.
Table 3. Comparison of Child Depression Inventory (CDI) scores and Kidscreen ratings in suicidal and nonsuicidal children: analysis of variance.

\begin{tabular}{lccccc}
\hline & \multicolumn{3}{c}{ No suicidality } & $\begin{array}{c}\text { Suicidal ideation or } \\
\text { attempts }\end{array}$ \\
\hline CDI & Mean & SD & Mean & SD & p-value \\
& 9.26 & 5.53 & 13.62 & 6.82 & 0.000 \\
& $\begin{array}{c}\text { Mean-T } \\
\text { value }\end{array}$ & SD & Mean-T value & SD & p-value \\
Kidscreen & 51.35 & 9.59 & 50.88 & 9.50 & 0.094 \\
Psychological & 50.40 & 9.63 & 48.14 & 9.67 & 0.001 \\
Well-Being & 50.43 & 9.46 & 48.17 & 9.75 & 0.001 \\
Moods \& Emotions & & & & & \\
Peers \& Social & 50.03 & 9.80 & 46.83 & 9.16 & 0.000 \\
Support & 50.36 & 9.73 & 48.36 & 9.82 & 0.001 \\
Parent Relation/ & 50.65 & 10.27 & 47.38 & 9.55 & 0.000 \\
Home Life & 51.87 & 5.29 & 50.24 & 9.51 & 0.093 \\
Self Perception & 50.61 & 9.97 & 50.8 & 9.95 & 0.522 \\
Autonomy & 50.31 & 9.40 & 50.2 & 9.74 & 0.620 \\
School Environment & & & & &
\end{tabular}

*(s) Standard deviation.

pecially concerning moods and emotions, peers and social support, parent relation/home life, self-perception and autonomy. No significant differences were found with the analysis of variance in others subscales of Kidscreen (physical well-being, psychological well-being, school environment, social acceptance and financial resources).

\subsection{Characteristics of the Ten Suicide Attempters}

Table 4 shows the characteristics of the ten children who had ever made at least one suicide attempt. The methods of suicide attempts were: overdose of pills (4), overdose of pills together with alcohol (3), cutting wrists (2) and one attempt to hang oneself. Among the attempters, seven were girls. The age range was 10 - 13 years and the mean age 12 years. In this group, three profiles can be spotted:

Severe impairment:

- Only one child, a boy, 13 years old (13 y.o) present at the same time depression disorder and a bad QOL in each domains of life.

- Four children (a boy, 13 y.o and 3 girls, 11 and 12 y.o $\times 2$ ) with bad QOL in nine or ten domains and criteria for depression (except for one (girl) of them). Mild-minimal impairment:

- A boy (12 y.o) and a girl (10 y.o) have no depression symptom and present a bad QOL in only 2 domains each.

None impairment:

- Surprisingly, three girls presenting suicide attempt by overdose of pills have no depression symptom and 
Table 4. Characteristics of children having attempted suicide.

\begin{tabular}{|c|c|c|c|c|c|c|c|c|c|c|c|c|c|c|}
\hline Gender & Age & $\begin{array}{l}\text { Method } \\
\text { S.A }\end{array}$ & Depression & $\begin{array}{l}\text { Poor } \\
\text { QOL }\end{array}$ & $\begin{array}{l}\text { Bad Physical } \\
\text { Well-being }\end{array}$ & $\begin{array}{c}\text { Bad } \\
\text { Psychol.l } \\
\text { Well-being }\end{array}$ & $\begin{array}{c}\text { Bad } \\
\text { Moods \& } \\
\text { Emotions }\end{array}$ & $\begin{array}{c}\text { Bad } \\
\text { Peers \& } \\
\text { Social } \\
\text { Support }\end{array}$ & $\begin{array}{c}\text { Bad } \\
\text { Parent } \\
\text { Relation } \\
\text { Home } \\
\text { life }\end{array}$ & $\begin{array}{c}\text { Bad } \\
\text { Self } \\
\text { Perception }\end{array}$ & $\begin{array}{c}\text { Poor } \\
\text { Autonomy }\end{array}$ & $\begin{array}{l}\text { Bad School } \\
\text { Environment }\end{array}$ & $\begin{array}{c}\text { Bad } \\
\text { Social } \\
\text { Acceptance }\end{array}$ & $\begin{array}{c}\text { Poor } \\
\text { Financial } \\
\text { Resources }\end{array}$ \\
\hline M & 13 & $\begin{array}{c}\text { Pills + } \\
\text { alcohol }\end{array}$ & $\mathrm{x}$ & $\mathrm{x}$ & $\mathrm{x}$ & $\mathrm{x}$ & $\mathrm{x}$ & $\mathrm{x}$ & $\mathrm{x}$ & $\mathrm{x}$ & $\mathrm{x}$ & $\mathrm{x}$ & $\mathrm{x}$ & $\mathrm{x}$ \\
\hline M & 13 & Hanging & $\mathrm{x}$ & $\mathrm{x}$ & $\mathrm{x}$ & $\mathrm{x}$ & $\mathrm{x}$ & - & $\mathrm{x}$ & $\mathrm{x}$ & $\mathrm{x}$ & - & - & $\mathrm{x}$ \\
\hline M & 12 & Cutting & - & - & $\mathrm{x}$ & - & - & - & - & $\mathrm{x}$ & - & - & - & - \\
\hline $\mathrm{F}$ & 11 & Pills & - & $\mathrm{x}$ & - & - & $\mathrm{x}$ & $\mathrm{x}$ & $\mathrm{x}$ & $\mathrm{x}$ & $\mathrm{x}$ & $\mathrm{x}$ & $\mathrm{x}$ & $\mathrm{x}$ \\
\hline $\mathrm{F}$ & 12 & $\begin{array}{c}\text { Pills + } \\
\text { alcohol }\end{array}$ & $\mathrm{x}$ & $\mathrm{x}$ & $\mathrm{x}$ & $\mathrm{x}$ & $\mathrm{x}$ & $\mathrm{x}$ & $\mathrm{x}$ & $\mathrm{x}$ & $\mathrm{x}$ & $\mathrm{x}$ & - & - \\
\hline $\mathrm{F}$ & 13 & Pills & - & - & - & - & - & - & - & - & - & - & - & - \\
\hline $\mathrm{F}$ & 12 & Pills & - & - & - & - & - & - & - & - & - & - & - & - \\
\hline $\mathrm{F}$ & 12 & Pills & - & - & - & - & - & - & - & - & - & - & - & - \\
\hline $\mathrm{F}$ & 12 & $\begin{array}{l}\text { Pills + } \\
\text { alcohol }\end{array}$ & $\mathrm{x}$ & $\mathrm{x}$ & - & $\mathrm{x}$ & $\mathrm{x}$ & $\mathrm{x}$ & $\mathrm{x}$ & $\mathrm{x}$ & $\mathrm{x}$ & $\mathrm{x}$ & - & $\mathrm{x}$ \\
\hline $\mathrm{F}$ & 10 & Cutting & - & - & - & $\mathrm{x}$ & - & - & - & $\mathrm{x}$ & - & - & - & - \\
\hline
\end{tabular}

express a good QOL in each domains of life.

Not surprisingly, the lethaler method (hang oneself) is observed about the 13 years old boy with severe impair ment. Pills and alcohol had been observed about the older children (12 and 13 y.o) and pills only had been found for children without impairment. Cutting the wrist is observed about a girl (10 y.o) and a boy (12 y.o) and it was associated with no depression symptom and only two domains of QOL degraded.

\subsection{Suicide Attempters vs. Suicide Ideators and No Suicide-Related Behaviours}

In this group, the CDI total mean score was higher than in the group of suicidal ideation $(n=32)$ and, as expected, higher than in the group with no suicidality (mean scores 15.8; $12.94 ; 9.26$ respectively; $\mathrm{p}=0.000),(\mathrm{F}=9.318 ; 2$ $154 \mathrm{p}=0.000)$. Furthermore, in the Kidscreen-52 ratings, the difference (187.56 vs. 186.20) was not significant. Instead, there was significant difference between suicide attempters and the group with suicide ideation and the one with no suicidality in the sub-scores of Kidscreen (mean scores 186, 20; 187.56; 206.07 respectively; $\mathrm{p}=$ $0.001)(\mathrm{F}=6.875,2-154 \mathrm{p}=0.001)$.

\section{Discussion}

In this study, more than a quarter of the children had expressed either suicidal ideation or behaviour. These children with suicide-related behaviours were also those with significantly more severe depression symptoms and lower levels of quality of life compared to other children. The QOL domains the most associated with suicidality are Moods \& Emotions, Peers \& Social Support, Parent Relation/Home life, Self Perception and Autonomy. These domains with low satisfaction indicate problems of overall social functioning, which is in accordance with the findings of low social competence and low coping skills of adolescents who have made suicide attempts [26] (van der Kolk, 1991). Association between depressive symptoms and suicidality was clearly underlined: results show that $40 \%$ of children with suicide attempts, nearly $19 \%$ of children with suicide ideation and nearly $9 \%$ without suicidality had clinical symptoms of depression. So, the depressive symptom severity is confirmed as an important indicator of suicide risk according some previous researches $[27,28]$. Suicidality was also associated with the age of the children. Ages under or equal 11 years were less suicidal than older children $(p=0.022)$. But, surprisingly, there was no difference in suicidality between the genders, whereas among the ten suicide attempters of the sample, the majority were girls. Sarkar et al. [29] observed in a study about suicidal phenomena in children versus adolescent that, with regard to gender, the under $12 \mathrm{~s}$ group had a higher percentage of males (57.3\%) compared to females $(42.7 \%)$. Moreover, in sample of adolescents, a female to male ratio of $2: 1$ is generally observed [30,31]. Finally, we have to consider the fact that in the little sample of ten suicide attempters, $30 \%$ of them had neither depressive symptom nor low QOL. The method used for these acts was overdose of pills, not such a lethal method but the death intention is there and we have to better understand in the future the causes of this phenomena (impulsivity? manipulation? others?).

\subsection{Clinical Implications}

The results of this study generally support our hypothesis concerning the association between suicidality, depres- 
sion and quality of life in children, which may have important clinical implications. It seems particularly important to encourage clinicians to investigate depression in prepubertal children but also to assess the suicidal tendencies of the under 13s children, in depressive context or not. Besides, we need to have a special interest for the perceived quality of life, which could be a useful construct for screening suicide-risk children. Effectively, quality of life seems to be a protective factor when it's perceived good (and so could moderate the risk of depression?) but also a factor of risk when a poor quality of life is perceived in several domains of life, in particular when it's in association with depressive symptoms but not only. Especially in absence of depression, QOL assessment may reveal the psychological ill-being of a child and allowed an adaptive care and prevention. So, understanding a child's context in terms of family, school and social functioning is critical. These findings may help to provide direction for targeted interventions to address these clinical risk factors. The high prevalence of early-onset depressive symptomatology, including suicidal ideation, occurring before puberty is concerning because of the consistent evidence linking preadolescent suicidal ideation and later suicide attempts in adolescence [32,33]. From a clinical perspective, screening tools for suicidality have been discussed for use in primary care with adolescents [34], but not with preadolescent children who may also be at risk. Given the results of this study, along with studies that suggest that earlier onset (before puberty) depression compared to later onset depression bodes poorly for children's later outcomes, there is a need for empirically based assessments of risk of suicidal behaviour for use by paediatricians during their regular medical visits with children. These assessments should allow clinicians to obtain information on identified risk factors, such as identified associated at a low satisfaction in everyday life: depressive symptoms, self-esteem, bullying, quality of parent's relationships and autonomy. Until such an instrument is available, primary health providers and front-line clinicians should actively question preadolescent children about suicidal ideation, particularly children who reported a poor quality of life and/or depressive symptoms. Because, without such direct inquiry, these children may not be identified by parents, teachers or caregivers as need of intervention.

\subsection{Limitations}

In this small sample, children's suicidal ideation and level of depressive symptomatology was only assessed via selfreport with the Children's Depression Inventory (CDI) rather than with a diagnostic interview based on the DSM-IV-TR (2000). Further, these data do not reflect the difference between children who experienced passive suicidal ideation and those who experienced more active suicidal ideation (e.g., had a plan). It could be important in the future to pay attention to this dimension, which could be the sign of urgency and/or danger in the model of suicidal crisis (cf. Conférence de consensus "La crise suicidaire: reconnaître et prendre en charge" 19 - 20th October 2000, Hôpital La Salpétrière, PARIS). Moreover in this study, suicidality was associated with children's perception on low quality of life, particularly with low scores on Moods \& Emotions, Peers \& Social Support, Parent Relation/Home life, Self Perception and Autonomy. But the type and context of the bad quality of life reported were not disaggregated by the measure used. Understanding the effects of context may be important for future research, as nature of parental relationship, domestic violence, bullying at school or bad self-esteem may be found to have a different impact on children.

\section{Conclusion}

Specific data describing suicidality in young children are relatively scarce and inconsistent [5] and most of the available literature describing suicidality in childhood fails to separate children younger than 12 years from adolescents for analysis and discussion [6]. However, current data suggest that suicide is the 12th leading cause of death in children younger than 12 years and is the fourth leading cause of death in children of 12 years old. In this study, which concerns psychiatric inpatients as well as normal-school children, it is clear that suicide attempts and ideations do occur in prepubertal children, and this fact bodes that such behavior can serve as a precursor to future suicide attempts during adolescence. This research suggests that children are as likely as older adolescents to commit suicide when exposed to risk factors. This risk seems to result from a pathological combination of child and environmental factors. Suicide-related behaviors are associated in this study with depressive symptoms and a low perceived quality of life, especially in Moods \& Emotions, Peers \& Social Support, Parent Relation/ Home Life, Self Perception and Autonomy Domains. Education about these risk factors should be part of the initial and ongoing training of all ED staff. Future research efforts should be directed toward clarifying the difference between children who experienced passive suicidal ideation and those who experienced more active suicidal ideation. Besides, future studies would have to add a diagnostic interview for assessing depression and to explore more exactly the QOL domains with low satisfaction with new constructs (emotions and affects; friendly relations; bullying; quality of parental relation; family functioning; self-esteem; feelings of autonomy/ confinement...). To conclude, it seems important and urgent to encourage pediatricians and front-line clinicians to use brief screening and comprehensive assessment tools for this vulnerable segment of our society. 


\section{REFERENCES}

[1] C. C. O’Leary, D. E. Franck, W. Grant-Knight, M. Beeghly, M. Augustyn, R. Rose-Jacobs, H. J. Cabral and K. Gannon, "Suicidal Ideation among Urban Nine and Ten Year Olds," Journal of Developmental \& Behavioral Pediatrics, Vol. 27, No. 1, 2008, pp. 33-39. doi:10.1097/00004703-200602000-00005

[2] M. Pelkonen and M. Marttinen, "Child and Adolescent Suicide: Epidemiology, Risk Factors, and Approaches to Prevention,” Paediatric Drugs, Vol. 5, No. 4, 2003, pp. 243-265.

[3] L. Connolly, "Suicidal Behavior: Does It Exist in Preschool Aged Children?” Irish Journal of Psychological Medicine, Vol. 16, 1999, pp. 72-74.

[4] C. R. Pfeffer, "Diagnosis of Childhood and Adolescent Suicidal Behavior: Unmet Needs for Suicide Prevention," Biological Psychiatry, Vol. 49, No. 12, 2001, pp. 10551061. doi:10.1016/S0006-3223(01)01141-6

[5] M. Pompili, I. Mancinelli, P. Girardi, A. Ruberto and R. Tatarelli, "Childhood Suicide: A Major Issue in Pediatric Health Care," Issues in Comprehensive Pediatric Nursing, Vol. 28, No. 1, 2005, pp. 63-68. doi:10.1080/01460860590916780

[6] C. L. Tishler, N. S. Reiss and A. R. Rhodes, "Suicidal Behavior in Children Younger than Twelve: A Diagnostic Challenge for Emergency Department Personnel,” Academic Emergency Medicine, Vol. 14, No. 9, 2007, pp. 810-818.

[7] R. Cohen-Sandler, A. L. Berman and R. A. King, "Life Stress and Symptomatology: Determinants of Suicidal Behavior in Children," Journal of the American Academy of Child \& Adolescent Psychiatry, Vol. 21, 1982, pp. 178186. doi:10.1016/S0002-7138(09)60917-1

[8] M. Walker, D. Moreau and M. M. Weissman, "Parents' Awareness of Children's Suicide Attempts," American Journal of Psychiatry, Vol. 147, No. 10, 1990, pp. 13641366.

[9] D. L. Hoyert, M. P. Heron, S. L. Murphy and H. C. Kung, "Deaths: Final Data for 2003," National Vital Statistics Reports, Vol. 54, No. 13, 2003, pp. 1-120.

[10] B. Groholt, O. Ekeberg, L. Wichstrom and T. Haldorsen, "Suicide among Children and Younger and Older Adolescents in Norway: A Comparative Study,” Journal of the American Academy of Child \& Adolescent Psychiatry, Vol. 37, No. 5, 1998, pp. 473-481. doi:10.1097/00004583-199805000-00008

[11] J. L. McIntosh, "Epidemiology of Adolescent Suicide in the United States,” In: R. W. Maris, S. S. Canetto, J. L. McIntosh and M. M. Silverman, Eds., Review of Suicidology, Guilford Press, New York, 2000, pp. 3-33.

[12] M. S. Gould, R. King, S. Greenwald, P. Fisher, M. SchwabStone, R. Kramer, A. J. Flisher, S. Goodman, G. Canino and D. Shaffer, "Psychopathology Associated with Suicidal Ideation and Attempts among Children and Adolescents," Journal of the American Academy of Child \& Adolescent Psychiatry, Vol. 37, No. 9, 1998, pp. 915-923. doi:10.1097/00004583-199809000-00011

[13] R. Thompson, E. Briggs, D. J. English, H. Dubowitz, L.
C. Lee, K. Brody, M. D. Everson and W. M. Hunter, "Suicidal Ideation among 8-Year-Olds Who Are Maltreated and at Risk: Findings from the LONGSCAN Studies,” Child Maltreat, Vol. 10, No. 1, 2005, pp. 26-36. doi:10.1177/1077559504271271

[14] C. R. Pfeffer, R. Lipkins, R. Plutchik and M. Mizruchi, "Suicidal Behavior in Latency Age Children," Journal of the American Academy of Child \& Adolescent Psychiatry, Vol. 27, No. 1, 1988, pp. 34-41. doi:10.1097/00004583-198801000-00006

[15] J. R. Asarnow, "Suicidal Ideating and Attempts during Middle Childhood: Associations with Perceived Family Stress and Depression among Child Psychiatric Inpatients,” Journal of Clinical Child Psychology, Vol. 21, No. 1, 1992, pp. 35-40. doi:10.1207/s15374424jccp2101_6

[16] P. L. Marciano and A. E. Kazdin, "Self-Esteem, Depression, Hopelessness, and Suicidal Intent among Psychiatrically Disturbed Inpatient Children,” Journal of Clinical Child \& Adolescent Psychology, Vol. 23, No. 2, 1994, pp. 151-160. doi:10.1207/s15374424jccp2302_5

[17] M. Kovacs, D. Goldston and C. Gastonis, "Suicidal Behaviors and Childhood-Onset Depressive Disorders: A Longitudinal Investigation," Journal of the American Academy of Child and Adolescent Psychiatry, Vol. 32, No. 1, 1993, pp. 8-20. doi:10.1097/00004583-199301000-00003

[18] N. Bolger, G. Downey, E. Walker and P. Steininger, "The Onset of Suicidal Ideation in Childhood and Adolescence,” Journal of Youth and Adolescence, Vol. 18, No. 2, 1989, pp. 175-190. doi:10.1007/BF02138799

[19] J. R. Asarnow, G. A. Carlson and D. Guthrie, "Coping Strategies, Self-Perceptions, Hopelessness, and Perceived Family Environments in Depressed and Suicidal Children,” Journal of Consulting and Clinical Psychology, Vol. 55, No. 3, 1987, pp. 361-366. doi:10.1037/0022-006X.55.3.361

[20] B. Yang and G. A. Clum, "Effects of Early Negative Life Experiences on Cognitive Functioning and Risk for Suicide: A Review,” Clinical Psychology Review, Vol. 16, No. 3, 1996, pp. 177-195. doi:10.1016/S0272-7358(96)00004-9

[21] M. Kovacs, "The Children Depression Inventory (CDI)," Psychopharmacology Bulletin, Vol. 21, No. 4, 1985, pp. 995-998.

[22] L. Moor and C. Mack, "Versions Françaises d'Echelles d'Evaluation de la Dépression," Neuropsychiatrie de l'Enfance et de l'Adolescence, Vol. 30, 1982, pp. 623626.

[23] L. Saint-Laurent, “Étude Psychométrique de l’Inventaire de Dépression Pour Enfants de Kovacs Auprès d'un Echantillon Francophone/Psychometric Study of Kovacs's Children's Depression Inventory with a French-Speaking Sample,” Canadian Journal of Behavioural Science, Vol. 24, No. 4, 1990, pp. 377-384. doi:10.1037/h0078990

[24] U. Ravens-Sieberer, A. Gosch, L. Rajmil, M. Erhart, J. Bruil, W. Duer, P. Auquier, M. Power, T. Abel, L. Czemy, J. Mazur, A. Czimbalmos, Y. Tountas, C. Hagquist, J. Kilroe and European Kidscreen Group, "The KIDSCREEN52 Quality of Life Measure for Children and Adoles- 
cents," Expert Review of Pharmacoeconomics \& Outcomes Research, Vol. 5, No. 3, 2005, pp. 353-364. doi:10.1586/14737167.5.3.353

[25] S. Robitail, M. C. Simeoni, M. Erhart, U. RavensSieberer, J. Bruil and P. Auquier, "Validation of the European Proxy KIDSCREEN-52 Pilot Test Health-Related Quality of Life Questionnaire: First Results,” Journal of Adolescent Health, Vol. 39, No. 4, 2006, pp. 596.e1-596.e10.

[26] B. A. Van der Kolk, C. Perry and J. L. Herman, "Childhood Origins of Self-Destructive Behavior,” American Journal of Psychiatry, Vol. 148, 1991, pp. 1665-1671.

[27] J. Gledhill and M. Hodes, "Depression and Suicidal Behavior in Children and Adolescents," Psychiatry, Vol. 7, No. 8, 2008, pp. 335-339. doi:10.1016/j.mppsy.2008.05.013

[28] M. F. Le Heuzet, P. Isnard, A. M. Badoual and M. Dugas, "Enfants et Adolescents Suicidants," Archives of Pediatrics, Vol. 2, No. 2, 1995, pp. 130-135. doi:10.1016/0929-693X(96)89872-1

[29] M. Sarkar, P. Byrne, L. Power, C. Fitzpatrick, M. Anglim, C. Boylan and S. Morgan, "Are Suicidal Phenomena in Children Different to Suicidal Phenomena in Adolescents? A Six-Year Review," Child and Adolescent Mental Health, Vol. 15, No. 4, 2010, pp. 197-203. doi:10.1111/j.1475-3588.2010.00567.X

[30] P. M. Lewinsohn, P. Rohde, J. R. Seeley and C. L. Bald- win, "Gender Differences in Suicide Attempts From Adolescence to Young Adulthood," Journal of the American Academy of Child \& Adolescent Psychiatry, Vol. 40, No. 4, 2001, pp. 427-434. doi:10.1097/00004583-200104000-00011

[31] D. A. Brent, M. Baugher, J. Bridge, T. Chen and L. Chiapetta, "Age- and Sex-Related Risk Factors for Adolescent Suicide," Journal of the American Academy of Child \& Adolescent Psychiatry, Vol. 38, No. 12, 1999, pp. 1497-1505. doi:10.1097/00004583-199912000-00010

[32] B. A. Bettes and E. Walker, "Symptoms Associated with Suicidal Behavior in Childhood and Adolescence," Journal of Abnormal Child Psychology, Vol. 14, No. 4, 1986, pp. 591-604. doi:10.1007/BF01260526

[33] D. B. Goldston, S. S. Daniel, D. M. Reboussin, B. A Reboussin, P. H. Frazier and A. E. Kelley, "Suicide Attempts among Formerly Hospitalized Adolescents: A Prospective Naturalistic Study of Risk during the First 5 Years after Discharge,” Journal of the American Academy of Child \& Adolescent Psychiatry, Vol. 38, No. 6, 1999, pp. 660-671. doi:10.1097/00004583-199906000-00012

[34] D. L. Frankenfield, P. M. Keyl, A. Gielen, L. S. Wissow, L. Werthamer and S. P. Baker, "Adolescent PatientsHealthy or Hurting? Missed Opportunities to Screen for Suicide Risk in the Primary Care Setting," Archives of Pediatrics and Adolescent Medicine, Vol. 154, No. 2, 2000, pp. 162-168. 